\title{
ASSESSMENT INDEKS LEAN DAN GREEN PADA SMES COKELAT BEAN TO BAR DI INDONESIA
}

\section{LEAN AND GREEN INDEX ASSESSMENT ON SMES CHOCOLATE BEAN TO BAR IN INDONESIA}

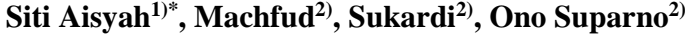 \\ 1)*Politeknik STMI, Kementerian Perindustrian RI \\ J1. Letjen Suprapto No 26 Cempaka Putih Jakarta Pusat, Indonesia 11650 \\ E-mail: lalita1712aisyah@gmail.com \\ ${ }^{2}$ Departemen Teknologi Industri Pertanian, Fakultas Teknologi Pertanian, Institut Pertanian Bogor, Indonesia \\ Makalah: Diterima 5 September 2018; Diperbaiki 20 November 2018; Disetujui 7 Desember 2018
}

\begin{abstract}
The development of chocolate Small Medium Enterprises (SMEs) is very strategic for Indonesia, where trade transactions value of processed cocoa and chocolate contributes to foreign exchange> USD 1 Billion/year. The demands of industrial operational systems that are slender (lean) and environmentally friendly (green) will be very important issues to be resolved particularly by SMEs with all their limitations. The purpose of this study was to determine the level of practice of lean and green on chocolate bean to bar SMEs in Indonesia and determine the importance of experts on the implementation of lean and green on chocolate bean to bar SMEs in Indonesia. The results of the analysis of the lean practice level on chocolate bean to bar SMEs with a scale of 1 5 , obtained a lean practice level obtained a scale of 3.85 and green practice of 3.39, while the scale of importance for lean is 4.41 and for green is 4.5. This indicates that the achievement index of lean and green practices are in the value of 3.62 which means that SMEs cocoa bean to bar Indonesia has not fully implemented the practices of lean and green.
\end{abstract}

Keywords : practice lean, practice green, SMEs, chocolate industry, bean to bar, LG Index

\section{ABSTRAK}

Pengembangan Small Medium Enterprises (SMEs) cokelat sangat strategis bagi Indonesia, dimana nilai transaksi perdagangan kakao olahan dan cokelat menyumbang devisa >USD 1 Billion/year. Tuntutan sistem operasional industri yang ramping (lean) dan ramah lingkungan (green) akan menjadi isu yang sangat penting untuk diselesaikan khususnya oleh SMEs dengan segala keterbatasannya. Tujuan penelitian ini adalah untuk menentukan tingkat praktik lean dan green pada SMEs cokelat bean to bar di Indonesia serta menentukan tingkat kepentingan dari para pakar terhadap pelaksanaan lean dan green pada SMEs cokelat bean to bar di Indonesia. Hasil analisis yang diperoleh dari tingkat praktik lean pada SMEs cokelat bean to bar yang berskala $1-5$ adalah sebesar 3,85 dan praktik green sebesar 3,39, sementara skala tingkat kepentingan untuk lean adalah sebesar 4,41 dan untuk green adalah 4,5. Dari persamaan untuk mencari indek diperoleh indeks praktik LG sebesar 3,62 yang artinya SMEs cokelat bean to bar Indonesia belum sepenuhnya mengimplematasikan praktik-praktik lean maupun green.

Kata kunci: praktik lean, praktik green, SMEs, industri cokelat, bean to bar, indeks LG

\section{PENDAHULUAN}

Persaingan bisnis yang semakin ketat menuntut industri untuk meningkatkan daya saing dan melakukan perbaikan berkesinambungan. Aktivitas yang tidak mempunyai nilai tambah (added value) diidentifikasi sebagai pemborosan (waste) dan terus dikurangi atau bahkan dihilangkan (Bhamu dan Singh Sangwan, 2014); (Rawabdeh, 2005). Kakao merupakan salah satu komoditas strategis bagi perekonomian Indonesia. Pengolahan kakao meliputi urutan proses mengubah bahan baku (biji kakao) menjadi produk setengah jadi kakao (cocoa liquor, cocoa butter dan cocoa powder). Pada skala global, kategori industri hilir kakao terbagi menjadi tiga jenis, grinding industry (industri pengolahan) kakao setengah jadi, industri kakao untuk industri (coverture) dan industri coklat konsumsi (makanan, minuman, confectionery). Pangsa pasar global untuk produk pengolahan kakao setengah jadi (grinding) cenderung sangat terkonsentrasi dan didominasi oleh perusahaan multinasional yang umumnya membuka cabang perusahaan di Indonesia. Industri kakao lebih rumit karena produk akhir sebagai produk cokelat merupakan penggabungan berbagai bahan baku lain seperti gula, susu dan aneka bahan lainnya dengan porsi beragam sebagai bahan tambahan (Takahashi et al., 2011); (Nabhani et al., 2015). Small Medium Enterprises (SMEs) pengolahan cokelat di Indonesia memiliki keterbatasan kapital dan sumber daya manusia dalam meningkatkan daya saingnya khususnya yang terkait dengan efisiensi operasional yang lean dan green. Praktik lean dan green tidak 
dapat dihindarkan seiring dengan tuntutan proses produksi yang ramping dan memberikan dampak yang tidak merusak lingkungan khususnya pada SMEs cokelat bean to bar. Pengetahuan kondisi tingkat pencapaian praktik lean dan green pada industri pengolahan cokelat khususnya bean to bar sangat penting untuk merencanakan perbaikanperbaikan strategis dan berkesinambungan di masa yang akan datang.

Pendekatan ramping (lean) adalah suatu pendekatan manajemen yang berdasarkan pada pengurangan biaya dan flexibilitas, fokus pada perbaikan proses melalui pengurangan dan eliminasi "waste" dan proses yang tidak memiliki nilai tambah (Vonderembse et al., 2006); (Melton, 2005); (Agarwal et al., 2006); (Cox dan Chicksand, 2005); (Hines dan Taylor, 2000). Lean mencakup semua proses melalui siklus hidup produk, dimulai dengan disain produk hingga penjualan produk, dari pesanan pelanggan sampai pengiriman (Anand dan Kodali, 2008), (Gurumurthy dan Kodali, 2008, 2011). Lean merupakan perangkat yang digunakan untuk memperbaiki proses, juga merupakan suatu philosopi dan sistem yang menggerakkan organisasi atau perusahaan, dimana apabila suatu organisasi memiliki proses, maka prinsip lean dapat diterapkan (Purba dan Aisyah, 2017). Penerapan konsep lean pada industri manufaktur sudah sangat banyak diimplementasikan, namun sangat sedikit yang diketahui tentang penerapan lean dalam industri makanan (Lehtinen dan Torkko, 2005) Industri makanan memiliki karakteristik yang berbeda dengan industri manufaktur pada umumnya, dimana memiliki masa kadaluarsa dan dapat menjadi busuk dalam jangka waktu tertentu. Dalam beberapa dekade terakhir lean telah menjadi katalis utama untuk inovasi organisasi dan inovasi proses di perusahaan manufaktur, meskipun aplikasi yang sukses dilaporkan di beberapa sektor industri, tetapi tentang penerapannya pada industri makanan dan minuman tidak banyak diketahui (Lopes et al., 2015). Lean melibatkan kecepatan proses dan bagaimana produk dapat dikirimkan lebih cepat kepada pelanggan dengan menghilangkan limbah dan juga dengan menggunakan lebih sedikit bahan dalam perakitan produk yang sebenarnya (Martínezdan Moyano, 2014). Penerapan lean pada industri makanan dan minuman dalam upaya meningkatkan kualitas makanan dan mengurangi biaya total sulit dicapai secara bersamaan dalam industri makanan halal (Ali et al., 2017) Untuk memastikan kelangsungan hidup biologis dan mencegah degradasi lingkungan lebih lanjut, manusia sampai pada kesimpulan bahwa hanya perlu menghasilkan makanan yang berkualitas, bersih dan aman (KosticNikoli dan Nikolic, 2013). Filosofi lean telah dikenal sebagai perubahan organisasi baru dan metode perbaikan, serta mekanisme pengurangan biaya (Näslund, 2008). Dengan menerapkan konsep lean, perusahaan makanan dapat meningkatkan nilai pelanggan (customer value) melalui pengurangan biaya atau melalui peningkatan nilai tambahan penyediaan layanan (Lehtinen dan Torkko, 2005).

Produksi hijau (Green production/ manufacturing) adalah suatu metode untuk meminimalkan limbah dan atau polusi yang disebabkan oleh proses produksi. Tidak ada perusahaan yang memiliki sumber daya manusia yang tidak terbatas untuk proyek-proyek perbaikan, prioritas harus diberikan kepada proyek-proyek yang memaksimalkan sinergi lean dan green dan menghilangkan beberapa bentuk limbah lean dan green secara bersamaan (Bergmiller dan McCright, 2009). Green production/manufacturing mendasarkan pada sistem produksi yang berkelanjutan (sustainable production system) dalam menghasilkan sebuah produk. Produk industri tersebut memiliki siklus hidup, mulai dari perancangan, pembuatan, distribusi, pemanfaatan dan sisa produk yang memiliki dampak kerusakan terhadap lingkungan dan kesehatan, serta mengkonsumsi sumber daya alam seminimal mungkin (material dan energi). Industri yang menerapkan industri hijau akan memiliki performa industri yang ramah lingkungan serta efisien dari segi ekonomi. Integrasi praktek lean dan green dapat memberikan manfaat bagi perusahaan (Dües et al., 2013) serta bisnis yang (Azevedo et al., 2013)

Saat ini pelaku industri di Indonesia maupun dunia dituntut harus mulai berwawasan industri hijau (Kemenperin, 2017). Isu ini penting dan mutlak untuk segera dilaksanakan agar tercapainya efisiensi produksi serta menghasilkan produk yang ramah lingkungan. Industri hijau adalah sebuah icon industri yang harus dipahami dan dilaksanakan, yaitu industri yang dalam proses produksinya menerapkan upaya efisiensi dan efektivitas dalam penggunaan sumber daya secara berkelanjutan. Pengembangan industri hijau dapat dilakukan melalui berbagai upaya, antara lain dengan penerapan produksi bersih (Subramanian dan Gunasekaran, 2015) konservasi energi (Chien dan Shih, 2007), efisiensi sumber daya, eco-design, proses daur ulang, low carbon technology, produksi dan packaging yang ramah lingkungan (Rusinko, 2007), serta penerapan ISO 14000 (Javier dan Oscar, 2005), (Zobel, 2015), Zobel (Zobel, 2013). Lean Green Manufacturing (LGM) adalah cara terbaik dan praktik yang akan datang untuk memajukan pengembangan industri skala kecil (SMEs) secara berkelanjutan (Nallusamy, 2016). Melalui penerapan industri hijau, maka akan terjadi efisiensi pemakaian bahan baku, energi dan air, sehingga limbah maupun emisi yang dihasilkan menjadi minimal dengan demikian proses produksi akan menjadi lebih efisien yang tentunya akan meningkatkan daya saing produk industri.

Disamping itu, pengembangan industri hijau merupakan salah satu usaha untuk mendukung komitmen Pemerintah Indonesia dalam menurunkan 
emisi Gas Rumah Kaca (GRK) sebesar 26\% pada tahun 2020 dibandingkan dengan kondisi saat ini, dan diharapkan akan dapat mencapai $41 \%$ dengan bantuan internasional. Komitmen ini membutuhkan usaha dan tindakan nyata yang menyeluruh, mencakup seluruh sektor pengemisi gas rumah kaca pada sektor-sektor produksi dan konsumsi prioritas untuk tindakan mitigasi dan adaptasi, termasuk sektor Industri.

Pengintegrasian praktik lean dan green yang dinyatakan dalam indeks LG adalah tujuan dari penelitian ini, hal ini penting dilakukan untuk melihat sejauh mana SMEs cokelat bean to bar Indonesia mengimplementasikan praktik-praktik lean dan green manufaktur.

\section{METODE PENELITIAN}

Metode dalam penelitian ini merupakan langkah-langkah yang dilakukan untuk mencapai tujuan dari penelitian. Adapun metodologi yang digunakan dalam penelitian ini pada Gambar 1.

Untuk mendapatkan indeks Lean dan Green (LG Indeks) pada industri SMEs cokelat bean to bar, langkah-langkah yang harus dilakukan adalah sebagai berikut :

1. Menentukan indikator yang merupakan praktikpraktik/implementasi dari lean dan green yang paling sesuai dilakukan pada SMEs cokelat bean to bar di Indonesia.

2. Setelah indikator ditentukan, maka langkah selanjutnya adalah menentukan tingkat kepentingan dari indikator-indikator lean maupun green yang harus diimplementasikan di SMEs cokelat bean to bar dan menilai sejauh mana indikator lean dan green pada SMEs cokelat bean to bar telah diimplementasikan. Kuesioner terbagi atas dua bagian yaitu pertama kuesioner menentukan tingkat kepentingan dari indikator lean dan green yang diberikan kepada 8 orang pakar di industri cokelat khususnnya SMEs cokelat bean to bar di Indonesia, yang terdiri dari akademisi maupun pemerintah serta SMEs sendiri. Hasil dari kuesioner ini adalah rata-rata penilaian, rangking dari masing-masing indikator dan serta di dapat bobot dari masingmasing indikator. Kuesioner kedua untuk menilai sejauh mana SMEs cokelat bean to bar Indonesia telah mengimplementasikan indikator-indikator lean dan green. Kuesioner ini diberikan kepada 4 SMEs cokelat bean to bar yang ada di Aceh, Bali, Jakarta dan Yogyakarta, yang mana keusioner diisi oleh pimpinan dari masingmasing SMEs dengan self assessment .

3. Langkah berikutnya adalah menilai sejauh mana SMEs cokelat bean to bar mempraktikan indikator-indikator lean dan green yang telah ditetapkam. Penilaian ini mengikuti persamaan (1) dan (2) yang pernah dilakukan oleh : (Azevedo et al., 2016).

$$
\begin{aligned}
& \left(B_{L}\right)_{j}=\sum_{i=1}^{y} w_{L i} x\left(P_{L i}\right)_{j} \\
& \left(B_{G}\right)_{j}=\sum_{i=1}^{y} w_{G i} x\left(P_{G i}\right)_{j} \ldots \ldots \ldots \ldots \ldots
\end{aligned}
$$

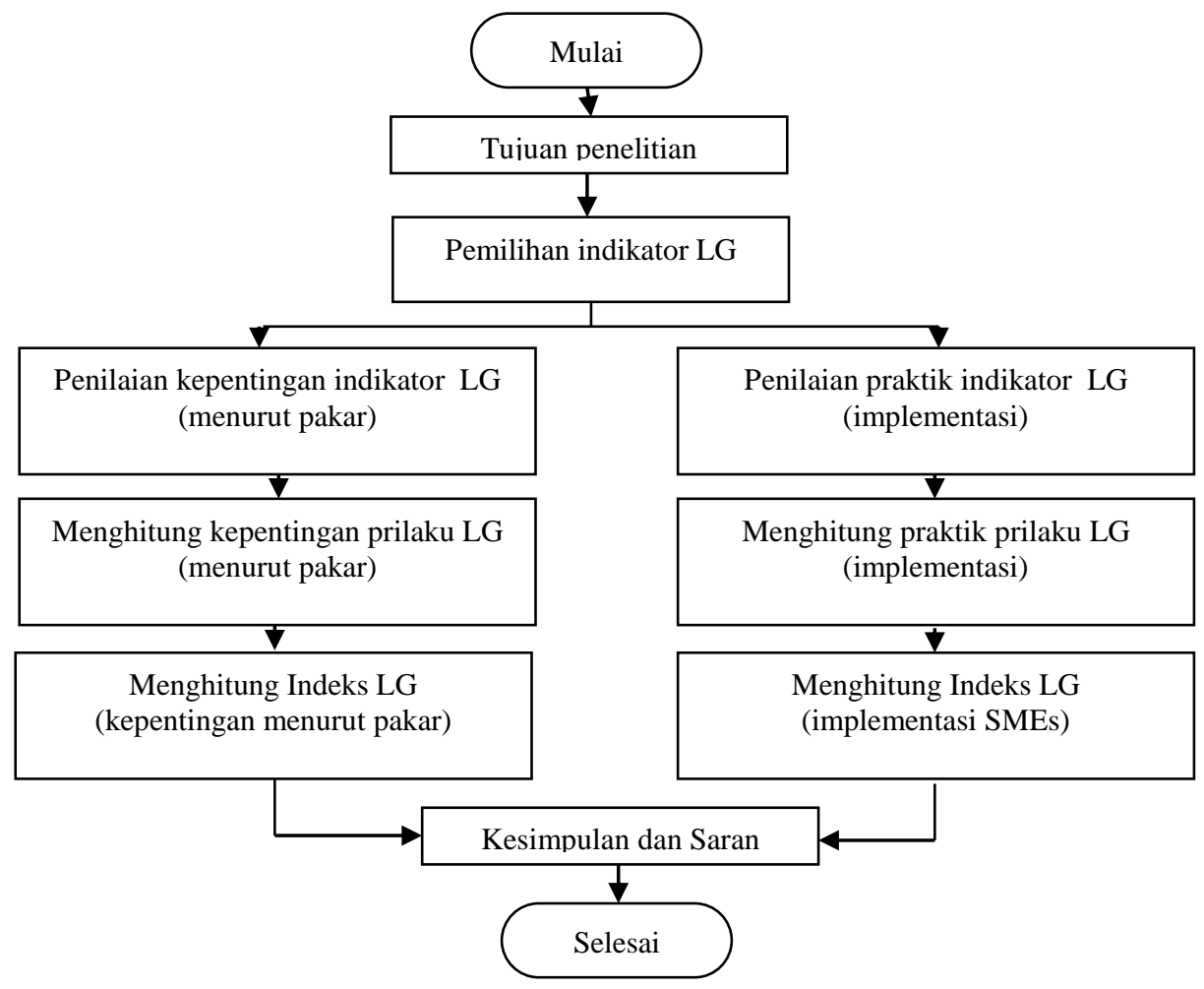

Gambar 1. Metodologi Penelitian 
Dimana :

$\checkmark\left(\mathrm{P}_{\mathrm{Li}}\right)_{\mathrm{j}}$ dan $\left(\mathrm{P}_{\mathrm{Gi}}\right)_{\mathrm{j}}$ mewakili masing-masing SMEs j dalam praktik lean dan green. Beberapa praktik y dipertimbangkan untuk lean dan green. Tingkat penerapan setiap praktik dinilai pada skala Likert 1 - 5 poin, dimana di bagi dua yaitu: pertama untuk penilaian tingkat kepentingan (pakar) dengan nilai terendah 1 yang berarti tidak penting dan tertinggi 5 yang berarti sangat penting. Kedua untuk penilaian pratik/implementasi dilapangan (SMEs cokelat bean to bar) dengan nilai terendah 1 berarti tidak memprakatikkan sama sekali dan tertinggi 5 yang berarti mempraktikkan sepenuhnya. $\mathrm{W}_{\mathrm{Li}}$ dan $\mathrm{W}_{\mathrm{Gi}}$ merupakan bobot kepentingan dari masing-masing indikator $\mathrm{i}$ dari lean dan green.

4. Langkah selanjutnya adalah menghitung indeks lean dan green atau yang disingkat dengan indeks LG dari masing-masing SMEs cokelat bean to bar $\left(\mathrm{LG}_{\mathrm{j}}\right)$ adalah indikator penjumlahan dari perkalian bobot perilaku lean dan green pada masingmasing SMEs.

$$
L G_{j}=0,5 \times\left(B_{L}\right)_{j}+0,5 \times\left(B_{G}\right)_{j} \ldots \ldots
$$

Dimana :

$\checkmark\left(\mathrm{B}_{\mathrm{L}}\right)_{\mathrm{j}}$ dan $\left(\mathrm{B}_{\mathrm{G}}\right)_{\mathrm{j}}$ merupakan simbol untuk perilaku masing-masing SMEs pada pendekatan lean dan green.
5. LG indeks pada masing-masing industri memiliki nilai antara 1-5 (1=industri tidak mempraktekkan lean maupun green sama sekali, $5=$ industri sangat mempraktikkan lean maupun green). Setelah diketahui LG indeks SMEs industri secara keseluruhan dengan menggunakan persamaan dibawah ini :

$$
L G_{I}=0,5 \times I_{L}+0,5 \times I_{G}
$$

Dimana :

$\checkmark \quad \mathrm{I}_{\mathrm{L}}$ dan $\mathrm{I}_{\mathrm{G}}$ merupakan simbol untuk perilaku SMEs cokelat bean to bar secara keseluruhan dalam hubungan dengan lean dan green.

$\checkmark$ Adapun untuk mencari $\mathrm{I}_{\mathrm{L}}$ dan $\mathrm{I}_{\mathrm{G}}$ dapat dilihat pada persamaan 5 dan 6 .

$I_{L}=\frac{\sum_{j=1}^{n}\left(B_{L}\right)_{j}}{n}$
$I_{G}=\frac{\sum_{j=1}^{n}\left(B_{G}\right)_{j}}{n}$

\section{HASIL DAN PEMBAHASAN}

Indikator dari masing-masing praktik lean dan green yang sesuai dengan kondisi SMEs cokelat bean to bar Indonesia dapat dilihat pada Tabel 1. Berdasarkan indikator-indikator lean dan green seperti pada Tabel 1 .

\begin{tabular}{|c|c|c|c|c|}
\hline \multicolumn{2}{|c|}{ Perilaku } & \multicolumn{2}{|r|}{ Indikator } & Referensi \\
\hline \multirow[t]{10}{*}{$\begin{array}{l}\mathrm{B}_{\mathrm{L}} \\
\text { Lean }\end{array}$} & $=$ & $\mathrm{P}_{\mathrm{L} 1}=$ & $\begin{array}{l}\text { Membangun sistem kualitas/ pemeriksaaan } \\
\text { mandiri }\end{array}$ & $\begin{array}{l}\text { (Shah dan Ward, 2003);(Doolen } \\
\text { 2005);(Gurumurthy dan Kodali, 2009) }\end{array}$ \\
\hline & & $\mathrm{P}_{\mathrm{L} 2}=$ & Mengurangi waktu siklus dan waktu setup & $\begin{array}{l}\text { (Shah dan Ward, 2003); (Doolen dan Hacker, 2005); } \\
\text { (Gurumurthy dan Kodali, 2009) }\end{array}$ \\
\hline & & $\mathrm{P}_{\mathrm{L} 3}=$ & Inovasi dalam Penilaian kinerja & (Doolen dan Hacker, 2005) \\
\hline & & $\mathrm{P}_{\mathrm{L} 4=}=$ & Meminimalkan persediaan sumber daya & (Anand dan Kodali, 2008) \\
\hline & & $\mathrm{P}_{\mathrm{L} 5}=$ & Memperpendek leadtime & $\begin{array}{l}\text { (Shah dan Ward, 2003); (Doolen dan Hacker, } \\
\text { 2005);(Gurumurthy dan Kodali, 2009) }\end{array}$ \\
\hline & & $\mathrm{P}_{\mathrm{L} 6=}=$ & Meningkatkan pemanfaatan sumber daya & (Doolen dan Hacker, 2005) \\
\hline & & $\mathrm{P}_{\mathrm{L} 7}=$ & TQM & $\begin{array}{l}\text { (Shah dan Ward, 2003);(Doolen dan Hacker, } \\
\text { 2005);(Gurumurthy dan Kodali, 2009);(Berry et al., 2015) }\end{array}$ \\
\hline & & $\mathrm{P}_{\mathrm{L} 8}=$ & JIT & $\begin{array}{l}\text { (Shah dan Ward, 2003); (Anand dan Kodali, 2008), (Berry } \\
\text { et al., 2015) }\end{array}$ \\
\hline & & $\mathrm{P}_{\mathrm{L} 9}=$ & Mengurangi lot size & $\begin{array}{l}\text { (Doolen dan Hacker, 2005); (Anand dan Kodali, 2008); } \\
\text { (Gurumurthy dan Kodali, 2009) }\end{array}$ \\
\hline & & $\mathrm{P}_{\mathrm{L} 10=}$ & Tenaga kerja yang multifungsi & $\begin{array}{l}\text { (Doolen dan Hacker, 2005); (Anand dan Kodali, 2008); } \\
\text { (Gurumurthy dan Kodali, 2009) }\end{array}$ \\
\hline \multirow[t]{10}{*}{$\begin{array}{l}\mathrm{B} \text { G } \\
\text { Green }\end{array}$} & $=$ & $P_{\mathrm{G} 1}=$ & $\begin{array}{l}\text { Kolaborasi dengan pemasok dan konsumen } \\
\text { dalam menjaga lingkungan }\end{array}$ & $\begin{array}{l}\text { (Lippman, 2001); (Hu dan Hsu, 2006); (Zhu dan Sarkis, } \\
\text { 2006; Zhu et al., 2007); (Vachon et al., 2006); (Holt dan } \\
\text { Ghobadian, 2009) }\end{array}$ \\
\hline & & $\mathrm{P}_{\mathrm{G} 2}=$ & Sertifikasi ISO 14000 & $\begin{array}{l}\text { (Zhu et al., 2008); (Vachon et al., 2006); (Holt dan } \\
\text { Ghobadian, 2009) }\end{array}$ \\
\hline & & $\mathrm{P}_{\mathrm{G} 3=}$ & & (Rao dan Holt, 2005); (Gonzalez et al., 2008) \\
\hline & & $\mathrm{P}_{\mathrm{G} 4}=$ & $\begin{array}{l}\text { Desain, inovasi, operasi dan kemasan yang } \\
\text { ramah lingkungan }\end{array}$ & $\begin{array}{l}\text { (Rao dan Holt, 2005); (Zhu et al., 2007); (Hu dan Hsu, } \\
\text { 2006) }\end{array}$ \\
\hline & & $\mathrm{P}_{\mathrm{G} 5}=$ & Label ramah lingkungan (eco) & (Rao dan Holt, 2005); (Gonzalez et al., 2008) \\
\hline & & $\mathrm{P}_{\mathrm{G} 6}=$ & $\begin{array}{l}\text { Menggunakan kembali atau mendaur ulang } \\
\text { bahan dan kemasan }\end{array}$ & $\begin{array}{l}\text { (Rao dan Holt, 2005); (Vachon et al., 2006); (Holt dan } \\
\text { Ghobadian, 2009) }\end{array}$ \\
\hline & & $\mathrm{P}_{\mathrm{G} 7}=$ & Meningkatkan kinerja lingkungan & (Rao dan Holt, 2005); (Vachon et al., 2006) \\
\hline & & $\mathrm{P}_{\mathrm{G} 8}=$ & milahan camnah & (Rao dan Holt, 2005); (Gonzalez et al., 2008) \\
\hline & & $\mathrm{P}_{\mathrm{G} 9=}$ & $\begin{array}{l}\text { Mendiskusikan perubahan kemasan saat ini } \\
\text { dengan konsumen }\end{array}$ & $\begin{array}{l}\text { (Rao dan Holt, 2005); (Vachon et al., 2006); (Holt dan } \\
\text { Ghobadian, 2009) }\end{array}$ \\
\hline & & $\mathrm{P}_{\mathrm{G} 10=}$ & mengurangi tingkat persediaan & (Paulraj, 2009), (Zhu et al., 2008) \\
\hline
\end{tabular}

Tabel 1. Indikator untuk menilai perilaku lean dan green SMEs cokelat bean to bar 


\section{Tingkat Kepentingan Indikator-Indikator Lean dan Green}

Hasil penilaianarata-rata oleh pakar terhadap tingkat kepentingan atas praktek lean dan green dapat dilihat pada Tabel 2. Tabel tersebut nampak bahwa nilai rata-rata tertinggi dari pakar yang menunjukan tingkat paling penting pada lean adalah indikator $\mathrm{P}_{\mathrm{L} 2}$ yaitu dengan cara mengurangi waktu siklus dan waktu setup. Sedangkan rata-rata tertinggi penilaian pakar pada green adalah Indikator $\mathrm{P}_{\mathrm{G} 4}$ yaitu dengan desain, inovasi, operasi dan kemasan yang ramah lingkungan yang merupakan indikator yang terpenting untuk green.

Untuk menguji apakah penilaian oleh 8 orang pakar tidak bertentangan, maka dilakukan uji statistik koefisien Koncordansi Kendalls. Hasil pengujian menunjukan bahwa untuk praktik lean nilai Kendalls sebesar 0,205 dan nilai asymp.sig adalah 0,098. Sementara praktik green menunjuk nilai uji Kendalls sebesar 0,288 dan nilai asymp sig sebesar 0,014. Hasil uji statistik Kendalls tersebut menyimpulkan bahwa responden pakar sepakat atas tingkat kepentingan indikator praktik lean dan green.

Untuk menghitung indeks kepentingan LG pada SMEs cokelat bean to bar Indonesia menurut pakar, perlu dicari terlebih dahulu nilai dari prilaku lean maupun green menurut para pakar. Berdasarkan persamaan (1) dan (2) maka di dapat nilai dari kepentingan indikator perilaku lean dan green menurut pakar yaitu masing-masing 4,41 dan 4,57, yang menunjukkan bahwa perilaku green lebih sangat penting di banding dengan perilaku lean. Secara keseluruhan berdasarkan persamaan (3) disimpulkan bahwa praktik lean dan green sangat penting (nilai skor 4,49) untuk implementasikan pada SMEs cokelat bean to bar di Indonesia sebagai upaya dalam meningkatkan daya saingnya.

\section{Pelaksanakan Praktik Lean dan Green}

Hasil penilaian dari praktik lean dan green pada ke 4 SMEs cokelat bean to bar yang ada di Aceh, Bali, Jakarta, Yoygakarta yang dilakukan oleh para pimpinan masing-masing SMEs dengan cara self assessment dapat dilihat pada Tabel 3.

Berdasarkan tabel 3 diketahui bahwa secara agregasi total rata-rata untuk praktik lean adalah 37,75 dan untuk praktik green sebesar 33 yang idealnya total rata-rata untuk masing-masing praktik adalah 50 yang artinya bahwa semua SMEs telah mengimplementasikan sepenuhnya praktik lean maupun green. Indikator praktik lean yang memberikan kontribusi terbesar terhadap praktik lean adalah indikator membangun sistem kualitas/pemeriksaan mandiri $\left(\mathrm{P}_{\mathrm{L} 1}\right)$, meminimalkan persediaan sumber daya $\left(\mathrm{P}_{\mathrm{L} 4}\right)$ dan TQM $\left(\mathrm{P}_{\mathrm{L} 7}\right)$, yang masing-masing memiliki nilai kontribusi sebesar 0,113 .

Tabel 3. Hasil penilaian implementasi lean dan green dari masing-masing SMEs cokelat bean to bar dalam rangking dan bobot

\begin{tabular}{|c|c|c|c|c|c|c|c|c|}
\hline \multirow[t]{2}{*}{ Perilaku } & \multirow[t]{2}{*}{ Indikator } & \multicolumn{4}{|c|}{$\begin{array}{l}\text { Penilaian level implementasi lean dan } \\
\text { green (1 (tidak mempraktikan), } 2,3,4 \text {, } \\
5 \text { (memprakatikan sepenuhnya)) }\end{array}$} & \multirow[t]{2}{*}{$\begin{array}{c}\text { Rata- } \\
\text { rata }\end{array}$} & \multirow[t]{2}{*}{ Kontribusi } & \multirow[t]{2}{*}{$\begin{array}{l}\text { Peringkat } \\
\text { kontribusi }\end{array}$} \\
\hline & & Aceh & Bali & Jakarta & Yogya & & & \\
\hline \multirow{11}{*}{$\begin{array}{c}\text { Praktik } \\
\text { lean }\end{array}$} & $\mathrm{P}_{\mathrm{L} 1}$ & 3 & 5 & 5 & 4 & 4,25 & 0,113 & 1 \\
\hline & $\mathrm{P}_{\mathrm{L} 2}$ & 2 & 4 & 5 & 5 & 4,00 & 0,106 & 2 \\
\hline & $\mathrm{P}_{\mathrm{L} 3}$ & 2 & 4 & 4 & 4 & 3,50 & 0,093 & 4 \\
\hline & $\mathrm{P}_{\mathrm{L} 4}$ & 3 & 5 & 5 & 4 & 4,25 & 0,113 & 1 \\
\hline & $\mathrm{P}_{\mathrm{L} 5}$ & 3 & 4 & 4 & 4 & 3,75 & 0,099 & 3 \\
\hline & $\mathrm{P}_{\mathrm{L} 6}$ & 2 & 5 & 5 & 4 & 4,00 & 0,106 & 2 \\
\hline & $\mathrm{P}_{\mathrm{L} 7}$ & 2 & 5 & 5 & 5 & 4,25 & 0,113 & 1 \\
\hline & $\mathrm{P}_{\mathrm{L} 8}$ & 3 & 4 & 4 & 5 & 4,00 & 0,106 & 2 \\
\hline & $\mathrm{P}_{\mathrm{L} 9}$ & 2 & 3 & 4 & 3 & 3,00 & 0,079 & 5 \\
\hline & $\mathrm{P}_{\mathrm{L} 10}$ & 2 & 3 & 3 & 3 & 2,75 & 0,073 & 6 \\
\hline & \multicolumn{5}{|c|}{ Total } & 37,75 & & \\
\hline \multirow{11}{*}{$\begin{array}{c}\text { Praktik } \\
\text { green }\end{array}$} & $\mathrm{P}_{\mathrm{G} 1}$ & 2 & 4 & 4 & 3 & 3,25 & 0,098 & 3 \\
\hline & $\mathrm{P}_{\mathrm{G} 2}$ & 3 & 4 & 5 & 3 & 3,75 & 0,114 & 2 \\
\hline & $\mathrm{P}_{\mathrm{G} 3}$ & 3 & 3 & 3 & 3 & 3,00 & 0,091 & 4 \\
\hline & $\mathrm{P}_{\mathrm{G} 4}$ & 1 & 3 & 4 & 2 & 2,50 & 0,076 & 5 \\
\hline & $\mathrm{P}_{\mathrm{G} 5}$ & 2 & 3 & 3 & 2 & 2,50 & 0,076 & 5 \\
\hline & $\mathrm{P}_{\mathrm{G} 6}$ & 2 & 5 & 5 & 4 & 4,00 & 0,121 & 1 \\
\hline & $P_{\mathrm{G} 7}$ & 3 & 4 & 5 & 3 & 3,75 & 0,114 & 2 \\
\hline & $\mathrm{P}_{\mathrm{G} 8}$ & 3 & 3 & 3 & 3 & 3,00 & 0,091 & 4 \\
\hline & $\mathrm{P}_{\mathrm{G} 9}$ & 3 & 5 & 4 & 4 & 4,00 & 0,121 & 1 \\
\hline & $\mathrm{P}_{\mathrm{G} 10}$ & 2 & 3 & 4 & 4 & 3,25 & 0,098 & 3 \\
\hline & \multicolumn{5}{|c|}{ Total } & 33 & & \\
\hline
\end{tabular}


Indikator menggunakan kembali atau mendaur ulang bahan dan kemasan $\left(\mathrm{P}_{\mathrm{G} 6}\right)$ serta mendiskusikan perubahan kemasan saat ini dengan konsumen $\left(\mathrm{P}_{\mathrm{G} 9}\right)$ merupakan indikator praktik green yang memberikan kontribusi terbesar yaitu masingmasing 0,121 pada praktik green. Hasil tersebut berbeda dengan penelitian terdahulu yang dilakukan oleh (Azevedo et al., 2012; Azevedo et al., 2016) pada industri automotif yang mana pada indikator lean yang paling berpengaruh adalah indikator just in time. Begitu pula pada indikator green kontribusi yang paling besar adalah pada indikator mengurangi pengunaan energi dan menggunakan kembali dan mendaur ulang material yang ada.

Kontribusi dan peringkat praktik lean dan green dari masing-masing SMEs dapat di lihat pada Tabel 4. Peringkat pertama pada praktik lean di Aceh adalah pada indikator membangun sistem kualitas/pemeriksaaan mandiri $\left(\mathrm{P}_{\mathrm{L} 1}\right)$ dan meminimalkan persediaan sumber daya $\left(\mathrm{P}_{\mathrm{L} 4}\right)$. Pada Aceh indikator yang berkontribusi paling rendah adalah tenaga kerja yang multifungsi $\left(\mathrm{P}_{\mathrm{L} 10}\right)$. Hal ini terjadi karena karakteristik tenaga kerja pada Aceh susah diatur dan diberi masukan, bila sudah bekerja pada satu bagian dia tidak akan mau pindah kebagian lain karena harus beradaptasi dan belajar lagi.

Indikator membangun sistem kualitas/ pemeriksaaan mandiri $\left(\mathrm{P}_{\mathrm{L} 1}\right)$, meminimalkan persediaan sumber daya $\left(\mathrm{P}_{\mathrm{L} 4}\right)$ dan TQM $\left(\mathrm{P}_{\mathrm{L} 7}\right)$ merupakan peringkat pertama dari praktik lean di Bali dan Jakarta, dan peringkat pertama di Yogyakarta adalah indikator TQM ( $\left.\mathrm{P}_{\mathrm{L} 7}\right)$. Pada implementasi green yang memberikan kontribusi terbesar di Aceh adalah indikator mendiskusikan perubahan kemasan saat ini dengan konsumen $\left(\mathrm{P}_{\mathrm{G} 9}\right)$, di Bali dan Yogyakarta adalah indikator menggunakan kembali atau mendaur ulang bahan $\left(\mathrm{P}_{\mathrm{G} 6}\right)$ dan kemasan serta mendiskusikan perubahan kemasan saat ini dengan konsumen $\left(\mathrm{P}_{\mathrm{G}}\right.$ ). Di Jakarta implementasi green rangking pertamanya adalah indikator menggunakan kembali atau mendaur ulang bahan dan kemasan $\left(\mathrm{P}_{\mathrm{G} 6}\right)$. Berdasarkan persamaan (5) dan (6) di dapat nilai perilaku lean dan green yang masing-masing nilainnya adalah 3,85 dan 3,39, hal ini berarti bahwa implementasi lean sebagian besar telah dipraktikkan dibanding dengan implementasi green. Hal ini sejalan dengan penelitian (Azevedo et al., 2016) yang menyatakan bahwa indikator lean lebih berkontribusi dibanding indikator green pada industri automotif. Dari hasil persamaan (4) diketahui bahwa indeks lean dan green (indeks LG) bernilai 3,62.

\section{Analisa Terhadap Indikator-Indikator yang Perlu Diperbaiki}

Setelah di dapat hasil peringkat dari masing-masing indikator pada penilaian kepentingan menurut pakar maupun penilaian implementasi pada SMEs cokelat bean to bar, maka data-data tersebut di plot ke dalam kuadran, sehingga dapat diketahui letak dari masing-masing indikator tersebut. Gambar 2a dan 2 b dapat dilihat terdapat 4 kuadran yang merupakan daerah dimana titik-titik antara peringkat kinerja SMEs dan peringkat kepentingan.

Tabel 4. Bobot dan peringkat praktik lean dan green dari masing-masing SMEs cokelat bean to bar

\begin{tabular}{|c|c|c|c|c|c|c|c|c|c|}
\hline \multirow{3}{*}{ Perilaku } & \multirow{3}{*}{ Indikator } & \multicolumn{8}{|c|}{ Bobot dan peringkat praktik lean dan green } \\
\hline & & \multicolumn{2}{|c|}{ Aceh } & \multicolumn{2}{|c|}{ Bali } & \multicolumn{2}{|c|}{ Jakarta } & \multicolumn{2}{|c|}{ Yogyakarta } \\
\hline & & Bobot & Peringkat & Bobot & Peringkat & Bobot & Peringkat & Bobot & Peringkat \\
\hline \multirow{10}{*}{$\begin{array}{c}\text { Praktik } \\
\text { lean }\end{array}$} & $P_{\text {L1 }}$ & 0,339 & 1 & 0,565 & 1 & 0,565 & 1 & 0,452 & 3 \\
\hline & $\mathrm{P}_{\mathrm{L} 2}$ & 0,212 & 5 & 0,424 & 3 & 0,530 & 2 & 0,530 & 2 \\
\hline & $P_{L 3}$ & 0,186 & 6 & 0,372 & 5 & 0,372 & 5 & 0,372 & 6 \\
\hline & $P_{L 4}$ & 0,339 & 1 & 0,565 & 1 & 0,565 & 1 & 0452 & 3 \\
\hline & $P_{L 5}$ & 0,297 & 3 & 0,396 & 4 & 0,396 & 4 & 0,396 & 5 \\
\hline & $P_{\text {L6 }}$ & 0,212 & 5 & 0,530 & 2 & 0,530 & 2 & 0,424 & 4 \\
\hline & $P_{L 7}$ & 0,226 & 4 & 0,565 & 1 & 0,565 & 1 & 0,565 & 1 \\
\hline & $\mathrm{P}_{\mathrm{L} 8}$ & 0,318 & 2 & 0,424 & 3 & 0,424 & 3 & 0,530 & 2 \\
\hline & PL9 $_{\text {L }}$ & 0,158 & 7 & 0,237 & 6 & 0,316 & 6 & 0,237 & 7 \\
\hline & $P_{L 10}$ & 0,146 & 8 & 0,219 & 7 & 0,219 & 7 & 0,219 & 8 \\
\hline \multirow{10}{*}{$\begin{array}{c}\text { Praktik } \\
\text { green }\end{array}$} & $\mathrm{P}_{\mathrm{G} 1}$ & 0,916 & 5 & 0,932 & 3 & 0,392 & 4 & 0,294 & 4 \\
\hline & $\mathrm{P}_{\mathrm{G} 2}$ & 0,342 & 2 & 0,456 & 2 & 0,570 & 2 & 0,342 & 3 \\
\hline & $\mathrm{P}_{\mathrm{G} 3}$ & 0,273 & 3 & 0,273 & 5 & 0,273 & 6 & 0,273 & 5 \\
\hline & $\mathrm{P}_{\mathrm{G} 4}$ & 0,076 & 7 & 0,228 & 6 & 0,304 & 5 & 0,152 & 6 \\
\hline & $\mathrm{P}_{\mathrm{G} 5}$ & 0,152 & 6 & 0,228 & 6 & 0,228 & 7 & 0,152 & 6 \\
\hline & $\mathrm{P}_{\mathrm{G} 6}$ & 0,242 & 4 & 0,605 & 1 & 0,605 & 1 & 0,484 & 1 \\
\hline & $\mathrm{P}_{\mathrm{G} 7}$ & 0,342 & 2 & 0,456 & 2 & 0,570 & 2 & 0,342 & 3 \\
\hline & $\mathrm{P}_{\mathrm{G} 8}$ & 0,273 & 3 & 0,273 & 5 & 0,273 & 6 & 0,273 & 5 \\
\hline & $\mathrm{P}_{\mathrm{G} 9}$ & 0,363 & 1 & 0,605 & 1 & 0,484 & 3 & 0,484 & 1 \\
\hline & $\mathrm{P}_{\mathrm{G} 10}$ & 0,196 & 5 & 0,294 & 4 & 0,392 & 4 & 0,392 & 2 \\
\hline
\end{tabular}




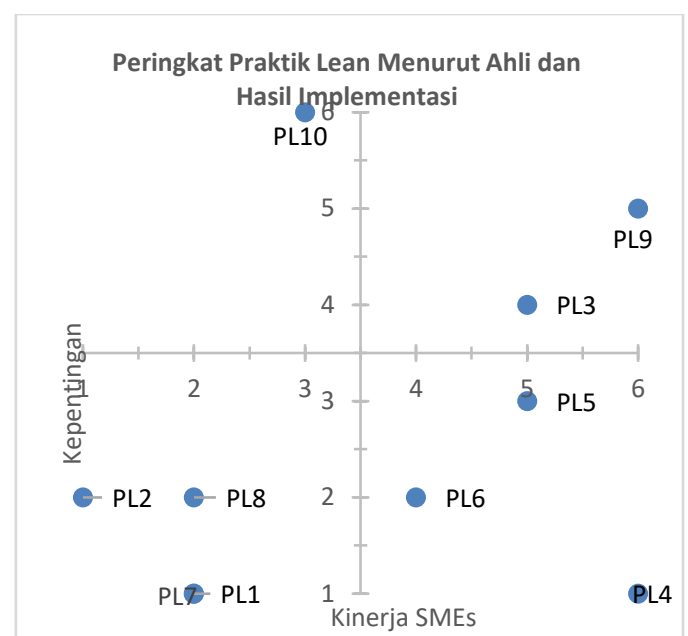

(a)

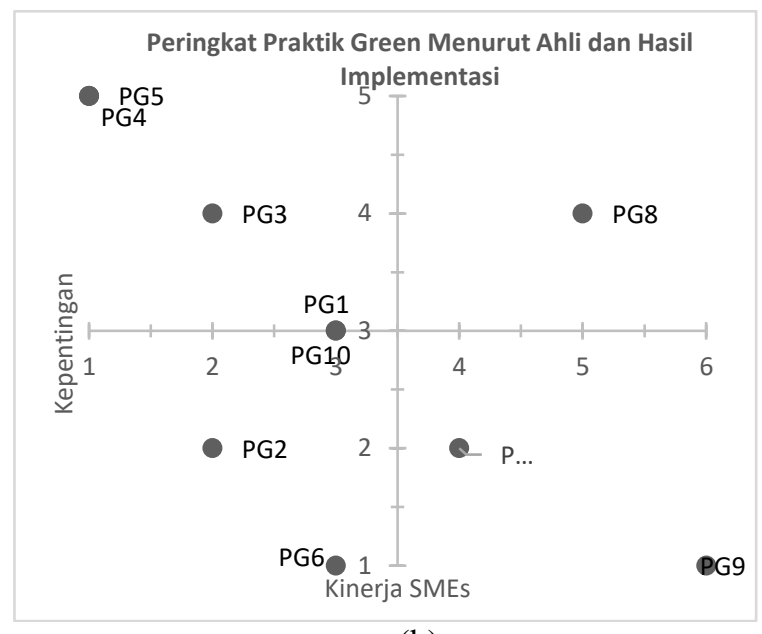

(b)

Gambar 2. (a) Peringkat kepentingan dan kinerja SMEs pada praktik lean, (b) Peringkat kepentingan dan kinerja SMEs pada praktik green

\section{KESIMPULAN DAN SARAN}

\section{Kesimpulan}

Berdasarkan hasil pengintegrasian praktik lean dan green dan perhitungan terhadap masingmasing indikator lean dan green, diperoleh hasil bahwa nilai indeks LG sebesar 3,62 yang artinya bahwa SMEs cokelat bean to bar yang ada di Indonesia belum sepenuhnya melakukan praktik lean maupun green. Dimana bila sepenuhnya praktik lean dan green dilakukan nilainya adalah 5,00. Hal ini sesuai dengan nilai Indeks LG pada tingkat kepentingan sebesar 4,49, yang artinya bahwa menurut pakar untuk memiliki daya saing SMEs cokelat bean to bar harus mengimplementasi sebagian besar praktik lean dan green. Indikatorindikator lean yang harus diperbaiki adalah indikator inovasi dalam penilaian kinerja $\left(\mathrm{P}_{\mathrm{L} 3}\right)$, mengurangi lot $\left(\mathrm{P}_{\mathrm{L} 9)}\right.$ dan tenaga kerja yang multifungsi $\left(\mathrm{P}_{\mathrm{L} 10)}\right.$ dan indikator-indikator green yang harus diperbaiki adalah pemilahan sampah $\left(\mathrm{P}_{\mathrm{G} 8}\right.$, penggunaan sumber daya alam $\left(\mathrm{P}_{\mathrm{G} 3)}\right.$ dan label ramah lingkungan (eco) $\left(\mathrm{P}_{\mathrm{G} 5) \text {. }}\right.$

\section{Saran}

Pada penelitian ini belum dilakukan penentuan kegiatan atau program apa saja yang harus SMEs cokelat bean to bar dari indikatorindikator lean dan green yang harus diiperbaiki. Perlu dilakukan penelitian lanjutan dengan menggunakan metode ISM atau AHP untuk mendapatkan secara rinci kegiatan atau program apa yang lakukan agar daya saing SMEs cokelat bean to bar dapat terus meningkat.

\section{DAFTAR PUSTAKA}

Agarwal A, Shankar R, dan Tiwari M K. 2006. Modeling the metrics of lean, agile and leagile supply chain: An ANP-based approach. European Journal of Operational Research. 173(1): 211-225. doi: 10.1016/j.ejor.2004.12.005.

Ali M H, Suleiman N, Tan K H, Alam S S. 2017. The Traction of Lean Production on Halal Food Integrity. MOJ Food Processing \& Technology. 5(4). doi: 10.15406/ mojfpt.2017.05.00136.

Anand G dan Kodali R. 2008. A conceptual framework for lean supply chain and its implementation. International Journal Value Chain Management. 2(3): 313-357.

Azevedo S G, Carvalho H, Duarte S, Cruz-Machado V. 2012. Influence of green and lean upstream supply chain management practices on business sustainability. IEEE Transactions on Engineering Management. 59(4): 753-765.

Azevedo S G, Govindan K, Carvalho H, CruzMachado V. 2013. Ecosilient Index to assess the greenness and resilience of the upstream automotive supply chain. Journal Cleaner Production. 56: 131-146. doi: 10.1016/j.jclepro.2012.04.011.

Azevedo S G, Pati N, Carvalho H, Cruz-Machado V. 2016. LARG index. Benchmarking: An International Journal. 23(6): 1472-1499. doi: 10.1108/bij-07-2014-0072.

Berry WL, Christiansen T, Bruun P, Ward P. 2015. Lean manufacturing: a mapping of competitive priorities, initiatives, practices, and operational performance in danish manufacturers.

Bhamu J, dan Singh Sangwan K. 2014. Lean manufacturing: literature review and research issues. International Journal Operations \& Production Management. 
34(7): 876-940. doi: 10.1108/ijopm-082012-0315.

Chien M dan Shih L-H. 2007. An empirical study of the implementation of green supply chain management practices in the electrical and electronic industry and their relation to organizational performances. International Journal Environmental Science and Technology. 4(3): 383.

Cox A dan Chicksand D. 2005. The limits of lean management thinking: multiple retailers and food and farming supply chains. European Management Journal. 23(6): 648-662. doi: https://doi.org/10.1016 /j.emj.2005.10.010.

Doolen TL dan Hacker ME. 2005. A Review of Lean Assessment in organizations: an exploratory study of lean practices by electronics manufacturers. Journal of Manufacturing Systems. 24(1): 55-67.

Dües CM, Tan KH, dan Lim M. 2013. Green as the new Lean: how to use Lean practices as a catalyst to greening your supply chain. Journal of Cleaner Production. 40: 93-100. doi: 10.1016/j.jclepro.2011.12.023.

Gary GBP dan Paul R McCright P. 2009. Are Lean and green programs synergistic? Proceedings of the Industrial Engineering Research Conference. 1155-1160.

Gonzalez P, Sarkis J, dan Adenso-Diaz B. 2008. Environmental management system certification and its influence on corporate practices: Evidence from the automotive industry. International Journal of Operations \& Production Management. 28(11): 1021-1041.

Gurumurthy A dan Kodali R. 2008. A multi-criteria decision-making model for the justification of lean manufacturing systems. International Journal Management Science and Engineering Management. 3(2): 100$118 . \quad$ doi: 10.1080/ 17509653.2008.10671039

Gurumurthy A dan Kodali R. 2009. Application of benchmarking for assessing the lean manufacturing implementation. Benchmarking: An International Journal. 16(2): 274-308. doi: 10.1108/ 14635770910948268.

Gurumurthy A dan Kodali R. 2011. Design of lean manufacturing systems using value stream mapping with simulation. Journal Manufacturing Technology Management. 22(4): 444-473. doi: 10.1108/ 17410381111126409.

Hines P dan Taylor D. 2000. Going lean. Cardiff, UK: Lean Enterprise Research Centre Cardiff Business School. 3-43.

Holt D dan Ghobadian A. 2009. An empirical study of green supply chain management practices amongst UK manufacturers. Journal Manufacturing Technology Management. 20(7): 933-956. doi: 10.1108/17410380910984212

Hu AH dan Hsu CW. 2006. Empirical study in the critical factors of green supply chain management (GSCM) practice in the taiwanese electrical and electronics industries. IEEE International Conference on Management Innovation and Technology. 853-857.

Javier G B dan Oscar GB. 2005. An analysis of the relationship between environmental motivations and ISO14001 certification. British Journal Management. 16(2): 133148.

Kostic-Nikoli S dan Nikolic. 2013. Lean six sigma in food industry. International Journal Basic \& Applied Sciences. 13(6): 21-31.

Lehtinen U dan Torkko M. 2005. The lean concept in the food industry: A case study of contract a manufacturer. Journal of Food Distribution Research. 36(3): 57-67.

Lippman S. 2001. Supply chain environmental management. Environmental Quality Management. 11-15.

Lopes RB, Freitas F, dan Sousa I. 2015. Application of Lean Manufacturing Tools in the Food and Beverage Industries. Journal Technol. Management Innovation. 10(3): 120-130.

Martínez-Jurado P J dan Moyano-Fuentes J. 2014. Lean Management, Supply Chain Management and Sustainability: A Literature Review. Journal of Cleaner Production. 85: 134-150. doi: 10.1016/j.jclepro.2013.09.042.

Melton T. 2005. The benefits of lean manufacturing. Chemical Engineering Research and Design. 83(6): 662-673. doi: 10.1205/cherd.04351.

Nabhani I, Daryanto A, Yassin M, Rifin A. 2015. Can Indonesia cocoa farmers get benefit on global value chain inclusion? a literature review. Asian Social Science. 11(18). doi: 10.5539/ass.v11n18p288.

Nallusamy S. 2016. Frequency analysis of lean manufacturing system by different critical issues in indian automotive industries. International Journal Engineering Research in Africa. 23: 181-187. doi: 10.4028/www.scientific.net/JERA.23.181

Näslund D. 2008. Lean, six sigma and lean sigma: fads or real process improvement methods? Business Process Management Journal. 14(3): 269-287. doi: 10.1108/ 14637150810876634.

Paulraj A. 2009. Environmental motivations: a classification scheme and its impact on environmental strategies and practices. 
Business Strategy and the Environment. 18(7): 453-468. doi: 10.1002/bse.612.

Rao P dan Holt D. 2005. Do green supply chains lead to competitiveness and economic performance? International Journal Operations \& Production Management. 25(9): $\quad 898-916 . \quad$ doi: $10.1108 / 01443570510613956$.

Rawabdeh IA. 2005. A model for the assessment of waste in job shop environments. International Journal Operations \& Production Management. 25(8): 800-822.

Rusinko CA. 2007. Green Manufacturing: An Evaluation of Environmentally Sustainable Manufacturing Practices and Their Impact on Competitive Outcomes. IEEE Transactions on Engineering Management. 54(3): 445-454.

Shah R dan Ward PT. 2003. Lean manufacturing: context, practice bundles, and performance. Journal Operations Management. 21(2): 129-149.

Subramanian N dan Gunasekaran A. 2015. Cleaner supply-chain management practices for twenty-first-century organizational competitiveness: Practice-performance framework and research propositions. International Journal Production Economics. 164: 216-233. doi: 10.1016/j.ijpe.2014.12.002.

Takahashi A R G, Santa-Eulalia L A d, Ganga G M D, Araujo JBd, Azevedo R C. 2011. Design of agile and green supply chains Proceedings the Industrial Engineering Research Conference.

Vachon S, Benn Lawson PDC, dan Klassen RD. 2006. Extending green practices across the supply chain. International Journal of Operations \& Production Managemen.
26(7): 795-821. doi: 10.1108/ 01443570610672248.

Vonderembse MA, Uppal M, Huang SH, Dismukes JP. 2006. Designing supply chains: Towards theory development. International Journal Production Economics, 100(2): 223-238. doi: https://doi.org/10.1016 /j.ijpe.2004.11.014.

Zhu Q dan Sarkis J. 2006. An inter-sectoral comparison of green supply chain management in China: Drivers and practices. Journal Cleaner Production. 4(5): 472-486. doi: https://doi.org/10.1016/ j.jclepro.2005.01.003.

Zhu Q, Sarkis J, dan Lai K-h. 2007. Green supply chain management: pressures, practices and performance within the Chinese automobile industry. Journal Cleaner Production. 15(11):1041-1052. doi: https://doi.org/ 10.1016/j.jclepro.2006.05.021.

Zhu Q, Sarkis J, dan Lai K-h. 2008. Confirmation of a measurement model for green supply chain management practices implementation. International Journal Production Economics. 111(2): 261-273. doi: https://doi.org/10.1016/j.ijpe. 2006.11.029.

Zobel T. 2013. ISO 14001 certification in manufacturing firms: a tool for those in need or an indication of greenness? Journal Cleaner Production. 43(Supplement C): $37-$ 44. doi: https://doi.org/10.1016/ j.jclepro. 2012.12.014.

Zobel T. 2015. The impact of ISO 14001 on corporate environmental performance: a study of Swedish manufacturing firms. Journal Environmental Planning and Management. 59(4): 587-606. doi: 10.1080/09640568.2015.1031882. 